\title{
Image Case : Pyloric Stenosis in Female Infant
}

Amin A.E. Elzaki ${ }^{1,2,3}$, Hamid Osman², Nglaa Fathy

${ }^{1}$ Alzaiem Alazhari University, Faculty of Radiological Science and Medical Imaging, Sudan

${ }^{2}$ Taif University, Faculty of Medical Applied Science, Radiological Science Department, KSA

${ }^{3}$ University of Medical Science and Technology UMST, Faculty of Radiological Science, Sudan

Corresponding author: Amin Elzaki email: aminzaki2000 @yahoo.com mobile: $+966533821879$

Received :26/1/2012

Accepted after

revision: $28 / 2 / 2012$
Pyloric stenosis also known as Infantile Hypertrophic Pyloric Stenosis (IHPS), is the most common cause of intestinal obstruction in infancy. IHPS occurs secondary to hypertrophy and hyperplasia of the muscular layers of the pylorus,

Hypertrophic Pyloric Stenosis (HPS) is commonly encountered in pediatric practice. The typical infant presents with non bilious projectile vomiting and dehydration (with hypochloremic metabolic alkalosis) if the diagnosis is delayed. Premature infants tend to present at 3-6 weeks from birth - not at 3-6 weeks from the due date-and these infants may have borderline normal muscle thickness, because they are comparatively smaller. Hypertrophic pyloric stenosis is rarely seen in children older than 6 months [1].

The etiology of IHPS is obscure but probably is multifactorial, involving genetic predisposition and environmental factors [2].

This condition accounts for one third of non bilious vomiting occurrences in infants and is the most common reason for laparotomy before age 1 year. A striking male preponderance is seen, with a male-to-female ratio of causing a functional gastric outlet obstruction. IHPS can be diagnosed by radiography and/or ultrasonography. An Endoscopy-Guided Balloon Dilatation (EGBD) is a new non-operative technique which can be used as a choice in treating IHPS.

4-6:1 [1]. Nuala et al. revealed in their study of 99 infants who underwent pyloromyotomy, that female developed the symptoms of pyloric stenosis later than males with a 6:1 male-female ratio [3].

We reported a 2 months female infant with a projectile vomiting in type referred to the $\mathrm{x}$-ray department. When a longitudinal abdominal ultrasound was performed a hypertrophic pyloric stenosis was seen (Image 1). Since the degree of confidence in a negative examination can be false in a patient who is seen early in the disease [1], a Barium meal was performed to confirm the diagnosis. The lateral barium contrast media showed a string sign indicating a IHPS (Image 2).

IHPS is treated by surgical intervention. An Endoscopy-Guided Balloon Dilatation (EGBD) can be used as a new method of nonoperative treatment for (IHPS) [4]. 


\section{REFERENCES}

1.Alweis A. Esophageal Polyps [Reflux 1.com, Education centre web site]. December 11, 2003. Available at: 1. Janet R. Imaging in Hypertrophic Pyloric Stenosis (Medscap.com, web site] May 27, 2011. Available

at: http://www.emedicine.medscape.com/article/40962 1-overview Accessed October 21, 2001.

2. Anthony P, Erin E. Infantile Hypertrophic Pyloric Stenosis [uptodae.com, web site ] September 27, 2010. Available at: http://www.uptodate.com/contents/infantilehypertrophic-pyloric-stenoss

Accessed November 27, 2011

3. Nuala Q, Andrew W, Irene M, Majella M. Pyloric Stenosis- Do Males and Females Present differently ? Ulster Med J 2011; 80(3): 145-147

4. Tam PKH, Carty H. Endoscopy-guided balloon dilatation for infantile hypertrophic pyloric stenosis. Pediatr Syrg Int 1991; 6:306-308

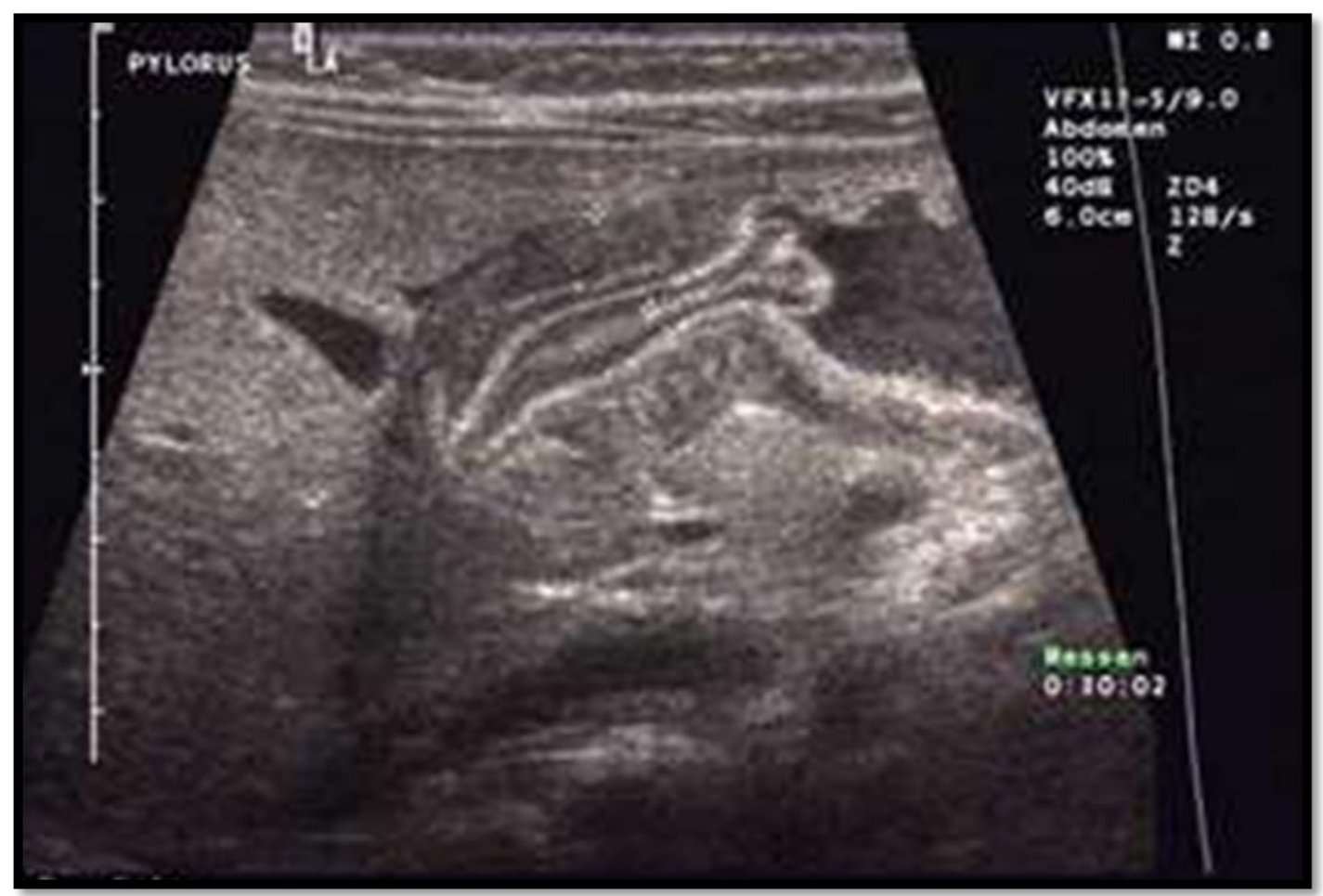

Image (1): Longitudinal ultrasound through a 2 months female infant showing an IHPS 


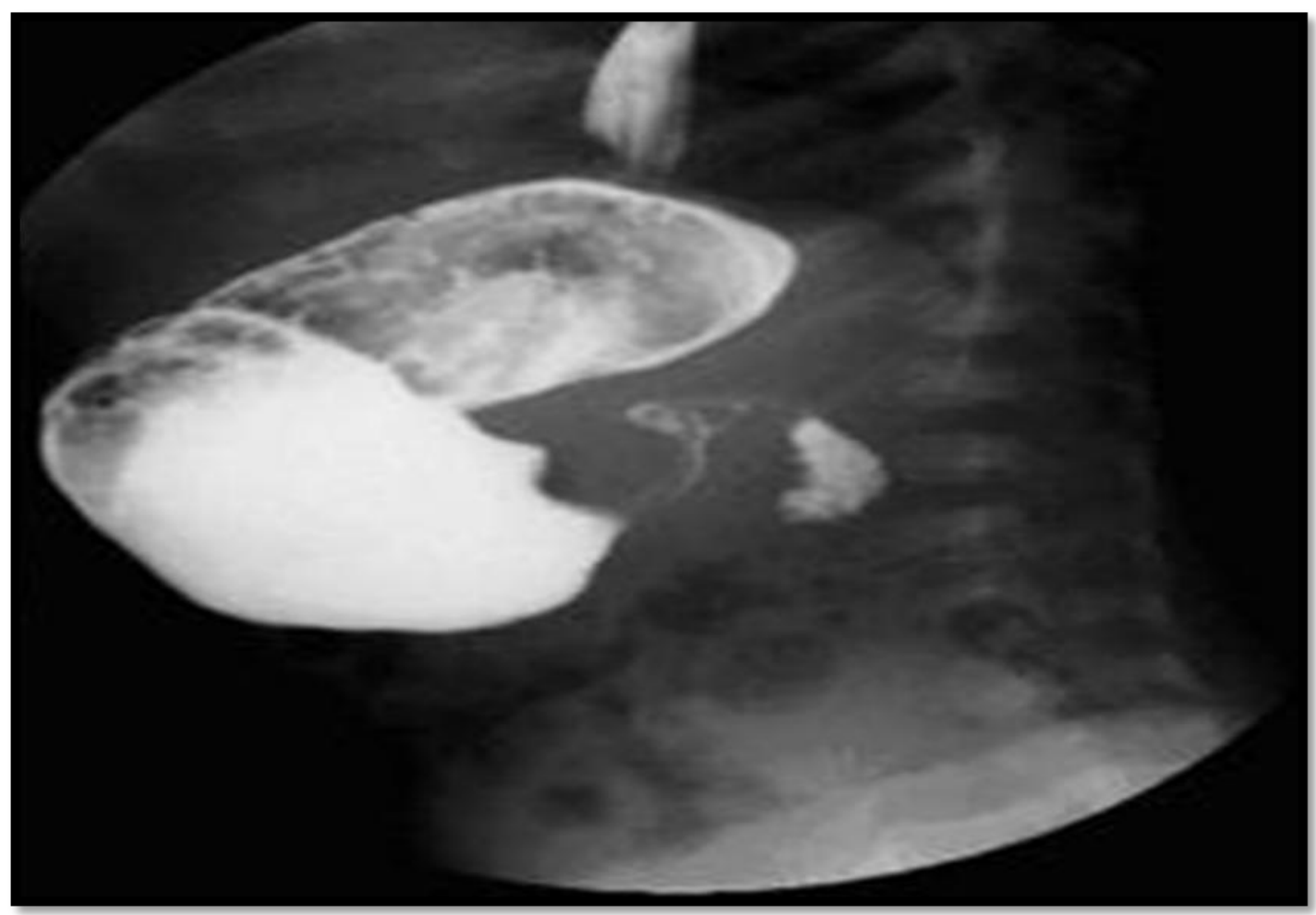

Image (2): A lateral barium meal for a 2 months female infant showing string sign indicating IHPS 